\title{
MAPPING PROPERTIES OF HARDY-TYPE OPERATORS INVOLVING GENERAL FUNCTIONS
}

\author{
PANKAJ JAIN AND BABITA GUPTA
}

Abstract. Weight characterizations are obtained for the boundedness and compactness of the operator

$$
(S f)(x)=u_{1}(x) \int_{a(x)}^{b(x)} v_{1}(t) f(t) d t+u_{2}(x) \int_{c(x)}^{d(x)} v_{2}(t) f(t) d t,
$$

where $u_{i}, v_{i}, i=1,2$, are certain general measurable functions (not necessarily non negative), between weighted Lebesgue spaces $L^{p}\left(I, w_{0}\right)$ and $L^{q}\left(I, w_{1}\right)$, where $1<p, q<\infty$ and $I=$ $(0, \infty)$.

Mathematics subject classification (2010): 46E35, $26 \mathrm{D} 10$.

Keywords and phrases: Hardy-type operators, boundedness, compactness.

\section{REFERENCES}

[1] H. P. Heinig And G. Sinnamon, Mapping properties of integral averaging operators, Studia Math., 129 (1998), 157-177.

[2] P. Jain And B. GuptA, Compactness of Hardy-Steklov operator, J. Math. Anal. Appl., 288 (2003), 680-691.

[3] P. JAIN, P. K. JAIN AND B. GUPTA, On certain double sized integral operators over multidimensional cones, Proc. A. Razmadze Math. Inst., 131 (2003), 39-60.

[4] P. JAIn, P. K. JAIN AND B. GUPTA, Compactness of Hardy type operators over star-shaped regions in $\mathbb{R}^{N}$, Canad. Math. Bull., 47 (2004), 540-552.

[5] P. JAIN, P. K. JAIN AND B. GUPTA, On certain weighted integral inequalities with mixed norm, Italian J. Pure Appl. Math., 17 (2005), 9-20.

[6] A. Kufner And L. E. Persson, Weighted Inequalities of Hardy Type, World Scientific, 2003.

[7] B. OpIC And A. Kufner, Hardy-Type Inequalities, Pitman Research Notes in Mathematics Series, Longman Scientific \& Technical Harlow, 1990.

[8] A. Kufner, L. Maligranda And L. E. Persson, The Hardy Inequality, About its History and Some Related Results, Vydavatelsky Sewis, Pilsen, 2007.

[9] V. D. STEPANOV, Weighted norm inequalities for integral operators and related topics, in Proceedings of the Spring School "Nonlinear Analysis, Function Spaces and Applications", 1994, 139-175.

[10] V. D. Stepanov, On the boundedness and compactness of a class of integral operators, Soviet Math. Dokl. 41 (1990), 468-470.

[11] P. A. Zharov, On a two-weight inequality, Generalization of inequalities of Hardy and Poincáre (in Russian), Trudy Math. Ins. Steklov 194 (1992), 97-110; translation in Proc. Steklov Inst. Math. 194 (4) (1993), 101-114. 